\title{
sciendo
}

\section{Is Human Capital in Higher Education Ready for Thailand 4.0: A Case Study of SSRUIC Students, Nakorn Pathom Education Center}

\author{
Kannapat Kankaew \\ Assistant Professor, Department of Airline Business, \\ International College; Suan Sunandha Rajabhat University (SSRUIC), \\ Nakorn Pathom Education Center, Thailand
}

Doi: 10.2478/jesr-2019-0038

\begin{abstract}
Presently, the Thai government has implemented its so-called Thailand 4.0 policy to move away from the middle-income trap to a value-based economy. Howbeit, human capital development is a crucial part for driving the policy's success. Hence, this study aims to assess the perception of Thailand 4.0, the factors affecting learning, and the effectiveness of teaching. A mixed method research approach was applied; this comprised researcher administered structured observation in the classroom and in-depth interviews. The AMOS was manipulated for structural equation modeling to test the relationship between exogenous and endogenous variables. The result revealed that 63 per cent of the respondents understand the policy at a fair level. Surprisingly, only 2 per cent were shown to have the highest degree of understanding the policy. Whilst, the top three factors affecting learning are enhancement from family, motives to learn, and passion to be successful in future careers. Whereas, the most preferable methods of learning are lecture, simulation and role-play. In summary, there are myriad methods for educating as well as multiple contexts affecting learning. In particular, the motives, values and culture of learners. As a result, teachers should motivate student more and prepare the teaching approaches that fit the specific learners of within each classroom.
\end{abstract}

Keywords: Thailand 4.0, Human Capital, Educational System, learning factors, Learning Method

\section{Introduction}

The main notions of the Thailand 4.0 policy are to enhance the economy and move away from the middle-income trap to a more value-based economy. The changes include switching from 'products' to 'innovations' and shifting from industrial drivers to technology and innovation forasmuch as the services will become more stressed from traditional services to high-value services There are two primary pillars for Thailand 4.0, (1) creating strength from within, which refers to innovation drivenprocesses, entrepreneur-driven positions, and community-driven propositions; and (2) creating a more extensive connection with the rest of the world, i.e. better connecting with the regional and global economy. For that reason, Thailand 4.0 is seen as a new engine for growth focusing on five main target industries as a part of the ten future industries, namely; food agriculture and bio-med, creative, culture and high-value services, digital and artificial intelligence \& embedded technology, and aviation. (Thairathonline, 2018, May 2).

Since the aviation industry is one of the targeted industries of Thailand 4.0, the government has planned to construct an "aerotropolis" at U-Tapao airport which will become a center of logistics called the EEC or Eastern Economic Corridor project. The airline industry in Thailand is also rapidly growing. For this reason, a large workforce is required. Many institutions are now subsequently opening airline business programs preparing workforces for this industry. Moreover, the bachelor 
degree in airline business program is becoming more popular among young Thais. In order to control education quality, all higher institutions are overseen by the Ministry of Education, which lately, has been changed to the Ministry of Higher Education, Science, Research and Innovation. Additionally, Suwit Maesincee (2017), a former Minister of the Prime Ministry Office, gave speech at the National Institute of Development Administration, 2017 as part of an academic seminar in which he said that the symmetry paradigm of Thailand 4.0 development relies on the balanced dimensions of economic, social environment and human intelligence. The primary driver of the Thailand 4.0 policy is human capital. He expects the policy to support the transformation of Thai people to be more knowledgeable and highly skills by obtaining a quality education. Also, it is stressed that they need to be able to learn through their own motivation, being accountable on social level, with better awareness of digital technologies and global industries.

\section{The Aim of Study}

Consequently, the researcher wanted to evaluate the airline business students' perception of Thailand 4.0 policy, the factors affecting on their learning, and the effectiveness of the approaches to their learning in aviation program at SSRUIC.

\section{Methodology}

A mixed method research technique has been applied to this study; for qualitative data, the researcher used in-depth interviews and focus group. Observation and content analysis were subsequently used to obtain qualitative data. Whilst, regarding the quantitative aspect of the study, the researcher used AMOS to run the Structural Equation Modeling (SEM) to test the causal relationship among different variables. The sample comprises students enrolled in airline business program (second year). There are total 8 classes with 185 students. Purposive sampling was employed, because the researcher teaches these students so the researcher can apply various teaching approaches. For example, gamification, case studies, and lectures. As well as, the researcher can often observe their behavior. For SEM, the fitness index was tested; including Chi square $<5.00, \mathrm{GFI}>0.96, \mathrm{NFI} \geq 0.98, \mathrm{RFI} \geq 0.95, \mathrm{CFI} \geq 0.97$ and $\mathrm{RMSEA}<0.087$.

\section{Literature Review}

Mankind is known to be complex in nature, but more intelligent than animals. They can destroy resources in response to their needs. However, in this destruction there might be creativity such as using technology for their comfort. Humans knows the Dos and Don'ts when it comes to logic thought associate with the impact of the actions they have done both in the short and long term; this applies to themselves, as well as society and the environment. Nevertheless, human spirit is subjective, which can be developed through education and learning which can, in turn, imrpove mankind for a better society. They have to know how to sacrifice, have mercy, and contribute on an individual level. A well-educated person will be of benefit to the promotion of a positive Thai society, in which people understand how to solve the problems creatively. There are three main subjects that Thai people should learn, namely science (due to the fact that we have to live in the world of multi-objects; social science, (because we stay in a chaos world, living and by with others we need to follow rules and regulations; and lastly and most importantly, humanity (due to the fact that this it closely connected with ethical and moral values. (Preecha, 2017)

Today, we live in a world of globalization where the flow of information is often referred to as "Big Data" data which can be identified by $3 \mathrm{Vs}$; Volume (the large quantity of data), Velocity (the fast speed of data that arrive), and Variety (data coming from a different sources) (Watson \& Nelson, 2014). This is because of the advancement of technology. So in a knowledge- based society, we see fast pace in terms of the fluctuations in knowledge and environment. From there on, investment in education for individuals is crucial for adapting young people to become highly skilled and knowledgeable in preparation for their future endeavors. As Schultz (1981) said expenditure in education is to invest in the future earning, ability and consumer satisfaction. The high expenditure 
that occurs in education is not a waste according to Fitz-Enz (2009), who proposed that investment in humans can be assessed by looking at return on investment (ROI) for both qualitative and quantitative results; such as the augmenting of service quality and the reduction of defect production in organizations. This is consistent with PwC (2019) which revealed its global consumer insights survey lately on ROX or return on experience, i.e., firms invest heavily in employee's experience (EX) by providing training and development, as well as IT platforms to embed, and engage employees with the organization's culture. The employees would deliver and perform to enhance customer experience (CX). This would make customers satisfied and return to use the service, thus, the organization certainly see an increase in profits.

The assumption of human capital is derived from an economic viewpoint comparing humans as physical tools and humans can be invested in by way of education, training and healthcare. Thereafter, these investments ultimately will improve knowledge, skills that enhance internal and external benefits (Becker, 1993). While, Davenport (1999) mentioned that human capital is comprised of three elements; those who deemed "capable" refers to knowledge, skills and talent; "behavior" refers to the behavior of oneself which reflects the value, ethics and norms of a person; and, lastly "effort" refers to the resources that one both physically and mentally contributes to perform the task. Whereas, the time is the resource that a person control differently. Baron \& Armstrong (2007), cited that human capital is associated with people who are able to develop and innovate processes in a firm by using their intangible knowledge, skills, capacity and abilities which have been invested in through education and training. Then, the idea of developing human resources (Nadler \& Nadler, 1989) is concerned with three activities including; training, which refers to the learning focus on current tasks; education, which refers to the learning emphasis on future tasks for the learner; and development, which is not a present task highlight.

Pokpong \& Supanat (2013) from the Thailand Development Research Institute (TDRI) presented their study on human capital development for better productivity, in which it was suggested that education is a primary issue for the new economy. The nation will experience growth with alongside improved quality, sustainability, innovation and equality of social life. Thais should possess $21^{\text {st }}$-Century skills consisting of work ethic, teamwork, problem-solving, and oral and written communication. The curriculum should incorporate core subjects, for example English, mathematic, economic history, governance and citizenship. The others include knowledge of the world, finance, innovation, information technology, and accountability. Whereas, Pitoon et al., (2017) recommended that the education for Thailand 4.0 should make the learner to be able to produce innovative products, have a critical mindset, become a smart consumer, and think responsibly and have social consciousness.

Tissana (2013) published her book on learning theory and types of teaching. The fundamental assumption of learning theory stems from behavioral and ethical thoughts. In the beginning, the appreciation or herbartianism believed that individuals learn from the perception of the five human senses, as well as physically feeling, imagination or analyzing. There are three levels of learning. These are sense of activity, characterization of memory, and conceptual thinking or understanding. The learner will link their experiences with their existing knowledge and will get more understanding. Thus, teaching shall include five processes; (1) preparation to arouse the interest and revise the lesson which has been previously learned; (2) presentation of new knowledge; (3) comparison and abstraction to expand new knowledge related with existing knowledge (4) generalization, which is to be concluded; and (5) the adaptation of knowledge. In the $20^{\text {th }}$ century, learning theory became more scientific; for instance, Intellectual Development Theory. Educational researchers believed that a child's learning and development was associated only according to their age. Or, as another example, Theory of Cooperative Learning divided students into small groups whereby they could help each other, meanwhile competing with other groups. This theory allows students to learn the values of teamwork and pick up social skills. There are many types of teaching as (Tissana, 2013) proposed, including lectures, demonstration, experiments, deduction, field trips, group discussion, role-play, case studies, games and simulation.

The Office of the Education Council of Thailand revealed its own study on the development of human competencies for the $21^{\text {st }}$ century. This study applied a structural equation modeling to analyze the causal relationships between learning factors for reading, calculating, and technology 
usage. There were various factors related to the three types of learning e.g. learner motives, their interests, family support, school environment, and friends etc., Whereas, Edgar Dale (1969) created a "cone" model of learning whereby it was assumed that 90 percent of people remember from what they have done, 70 per cent remember from what they have said, and 50 per cent remember from what they have seen \& heard. Also, 30 per cent, 20 per cent and 10 per cent came from what they have seen, heard and read respectively.

From the literature review, researcher has subsequently created a conceptual framework for this study consisting of different factors affecting learning (FLN) as input, learning \& development approach (DLN) as process, and outcome as the attributes of Thailand 4.0 (ATT), which is illustrated in the figure below;

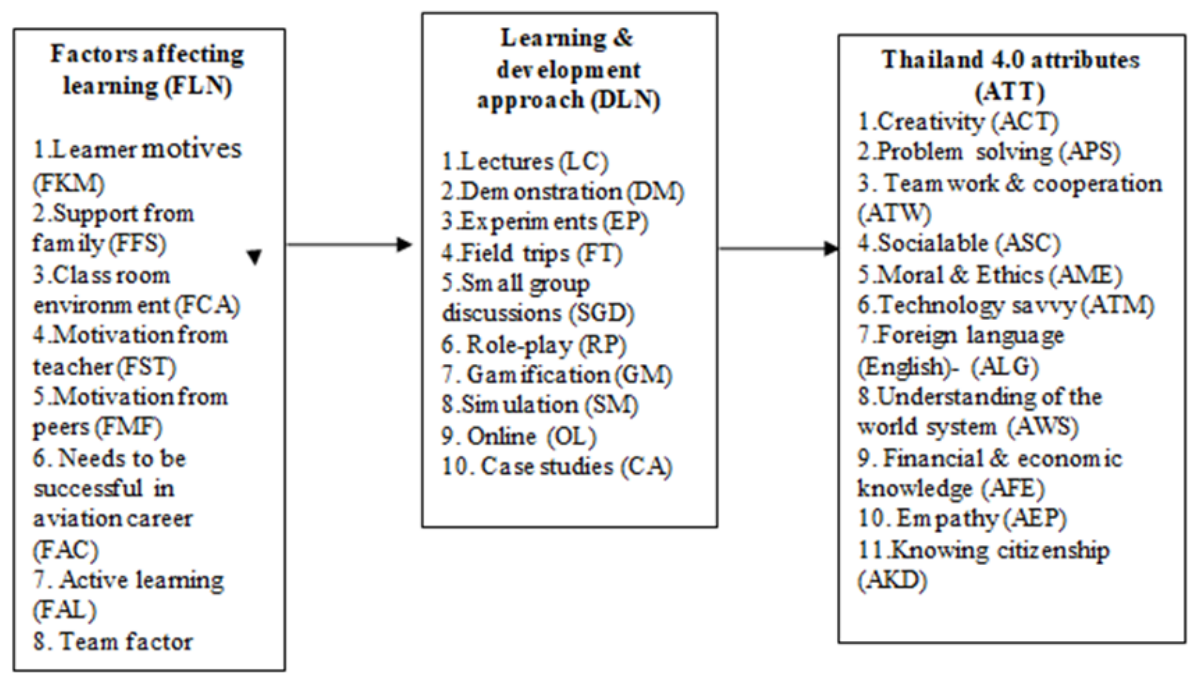

Figure 1: Conceptual Framework

\section{Result}

The first objective of this study was to assess the airline business students' at SSRUIC on their perception of the Thailand 4.0 policy. The results show that the highest percentage of students fall into the category of "moderate knowledge" about the policy at 63 per cent. Only 2 per cent of students had the highest degree of understanding of the policy. In contrast, 5 per cent of the students had no knowledge or understanding of the Thailand 4.0. It is worth noticing that the percentage of those who not aware of the policy were more than 50 per cent of the number of students who had highest understood. The researcher also conducted a focus group. Some students said

"I think it is concerned with political issues. I am getting bored..."

"I just wait and see."

"I think it is about long-term plan, it is in the future. So l'd rather focus on my study."

Howbeit, there were some students who thought that the EEC project will be beneficial to their future. Especially, the aerotropolis project, which will require a larger workforces. They want it to be finished as soon as possible.

From the conceptual framework, the researcher has segregated each of the tested variables starting from factors affecting learning (FLN). The results show that the support from family (FFS) has the highest affect on learning at 80 per cent, whereas self-motivation (FKM) and the needs to 
achieve success in an aviation occupation (FAC) have an effect on the learning at 69 per cent equally. Boonkong (2006) cited that family is the most important factor for the quality of human capital. This is because; the health and education of parents influence their child's values and ethics. As well as, (Monderna \& Voinarovska, 2019) disclosed that the personal motives and selfaccomplishment boost learning in the education process. However, the factor with the weakest correlation to learning was found to be motivation from teacher at significant level of 14 per cent.

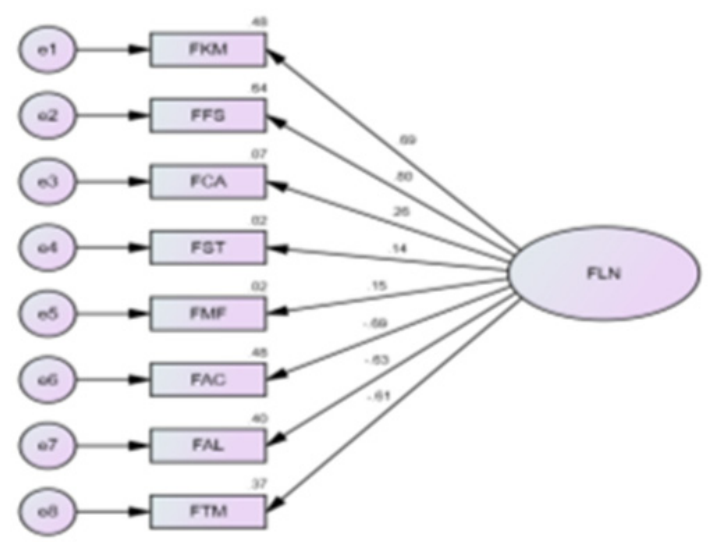

Figure 2: The causal relationshipbetween factors affecting learning

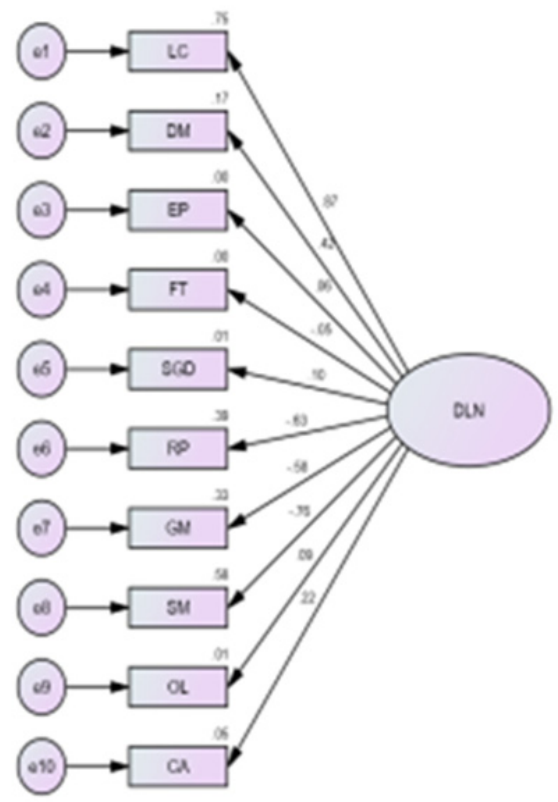

Figure 3: The causal relationship between learning \& development approaches

Figure 3 demonstrates the factors that influence learning and development (DLN). It can be seen that the sampling group prefer lectures (LC) which has the highest significant level in terms of effect on DLN at 87 per cent. This is followed, by simulation (SM) and role play (RP) which have the effect 
on respondents learning at a significant level 76 per cent and 63 per cent respectively. The qualitative method using a focus group was applied with the specific questions; "what makes you like lectures?" Some of the answers are, for example;

"I like to listen to the teacher to explain clearly, since there are many airlines' terminologies. Also, we are learning in English. If I lose my focus, I could not understand."

Though, some students like to learn by doing.

"I like to do, practical tasks after the lecture. I can learn from my real experience from doing."

The later part is the testing the attributes of Thailand 4.0 (ATT) in terms of what the characteristics of people be consisting from the sampling perspective. The results shown in Figure 4 affirm that problem-solving skills (APS) rank in at number one, followed by teamwork and cooperation (ATW), and the knowing of citizenship (AKD) with the significant effect level of 86 per cent, 84 per cent and 81 per cent, accordingly. However, as we can see, morals and ethics (AME) also have a highly significant level at 80 per cent, which is slightly lower than knowing citizenship. Knowing citizenship refers to one learning to live, adapt oneself, respect others and the law peacefully. And the question from focus group confirmed that what makes the respondents select APS, ATW, and AKD instead of technology savvy, financial and economic or foreign language. They revealed that;

"I study in the airline business program. And I think that it is important to solve problems for the passengers quickly. The passengers will be happy and come back to use service again."

"For me, I was born with existing technology already. So I can apply and use it easily. In any business, have creative problem-solving skills is more important. Because there are thousands of datasets and pieces of information to be analyzed and solved."

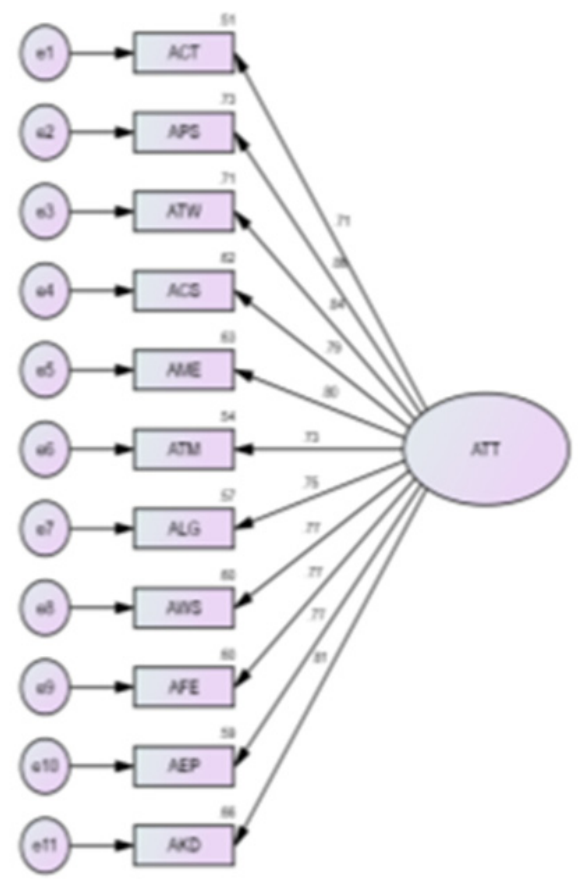

Figure 4: Thailand 4.0 attributes 


\section{Conclusion}

Finally, researcher has combined the SEM model as the conceptual framework presented, as shown in Figure 5 below. From the test of the model, it was found that the factors affecting learning and development are at a significant level of 25 per cent. While, learning and development can influence the attributes of Thailand 4.0 at only 15 per cent. It is worth noting that the FLN and DLN have few effects of influence on ATT. In order to develop the required quality of young Thais as a part of the Thailand 4.0 policy, all stakeholders should incorporate this information. Especially, this should start from the family level, which was shown to have the highest influence on students. Teachers should also be considered to have a more crucial role as a coach or mentor to motivate learners. Besides this, the most important issue is the explanation of the Thailand 4.0 policy, as well as the EEC (Eastern Economic Corridor) to students. Such explanations should focus on how these projects are essential to the country and their future. Principally, this involves those who want to work in the aviation and service industries.

The country needs to develop people to be more creative, and innovate. Teaching and learning should involve active learning or project-based learning. Institutions need to better cooperate with private or public companies that opportunities for students to research, and practice in real situations. Holding seminars on topic concerning Thailand 4.0 is also needed. Above all, student's research projects will enhance problem-solving skills for students systematically, innovatively, and also applying technology at the same time. Lastly, for morals and ethics, and social consciousness as being a good citizen; teachers can inspire learners by assigning volunteer projects which help other people as this would create enhanced networking of students and society, improving their empathy, morals and ethics, including teamwork.

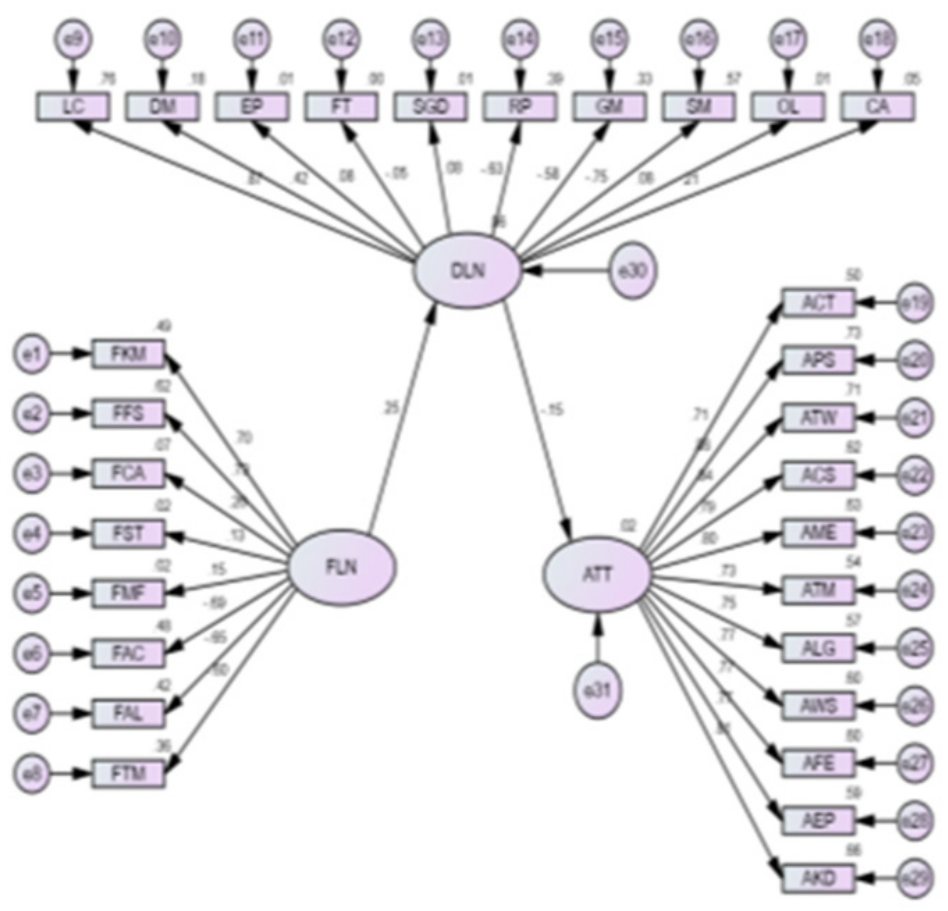

Figure 5: The relationship of FLN, DLN and ATT model 


\section{References}

Becker, S. G. (1993). Human Capital: A Theoretical and Empirical Analysis with Special Reference to Education $\left(3^{\text {rd }}\right.$ ed). London: The University of Chicago Press.

Baron, A., Armstrong, M. (2007). Human Capital Management: Achieving Added Value Through People. London: KOGAN PAGE.

Boonkong, H. (2006). Human Resources Economic. Bangkok: O.S. Printing House.

Dale, E. (1969). Audiovisual methods in teaching ( $3^{\text {rd }}$ ed.). NY: Dryden Press.

Davenport, O. T. (1999). Human Capital: What it is and Why People invest it. Oxford: Jossey-Bass Publisher.

Fitz-Enz, J. (2009). The ROI of Human Capital ( $2^{\text {nd }}$ ed). Shanghai: AMACOM

Monderne, E., Voinarovska, N. (2019). Promoting Personal Motivation within Professional Education. Journal of Educational and Social Research, 9(2), 1-7.

Nadler, L., Nadler, Z. (1989). Developing Human Resources (3 ${ }^{\text {rd }}$ ed). Oxford: Jossey-Bass Publisher.

Paitoon et, al. (2017). Thailand 4.0 Educational is more than Education $\left(4^{\text {th }} \mathrm{ed}\right)$. Educational College, University of Dhurakijbandit.

Pokpong,. Supanat. (2013). Human Capital Development for Better Productivity. Thailand Development Research Institute. Paper presented at New Development Model: Towards Quality Growth Based on Productivity Improvement Conference.

Preecha, C. (2017). Preecha's Perspective on Humanity, Social and Education. Bangkok: Sodsrisaditwong Foundation.

PwC. (2019). It's time for a consumer-centred metric: introducing 'return on experience'. Retrieved from www.pwc.com.

Schultz, W. T. (1981). Investing in People: The Economics of Population Quality. London: University of California Press.

Suwit, M. (2017, June 15). Sufficient Economic and Sustainable Development: A Paradigm for Thailand 4.0. Presented at National Institute Development Administration.

Tissana, K. (2013). Educational Theory and Process of Learning and Teaching for Best Practice (1 ${ }^{\text {th }}$ ed.). Bangkok: Chulalongkorn University Press.

Thairathonline. (2018, May 2). Thailand 4.0. Retrieved from http://www.thairath.co.th/content/613903.

Watson, M., Nelson, D. (2014). Managerial Analytics: An Applied Guide to Principles, Methods, Tools, and Best Practices. Singapore: Pearson.

\section{Appendix}
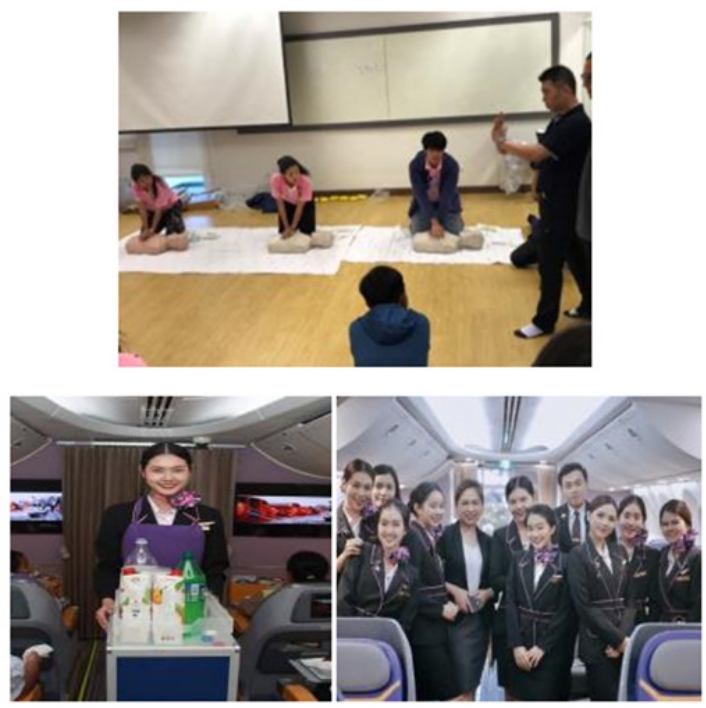

Figure 6: Active learning (CPR-Cardio-Pulmonary Resuscitation), and cabin mock-up simulation services 